\title{
Ser historiador del arte
}

\author{
María Viñas Benito Parra | historiadora del arte. Acento Cultural \\ Francisco José Cerceda Cañizares | Universidad de Castilla-La Mancha. Acento Cultural \\ Ricardo Ortega Olmedo | historiador del arte. Acento Cultural \\ Lucio Rodríguez Méndez | historiador del arte. Acento Cultural
}

URL de la contribución <www.iaph.es/revistaph/index.php/revistaph/article/view/3457>

Todo historiador del arte ha escuchado en numerosas ocasiones lo preciosa e interesante que es esta carrera. La realidad es que la sociedad no conoce qué lugares debe ocupar esta profesión y, lo peor de todo, no hemos hecho lo suficiente aquellos que decidimos tomar este camino.

Para encontrar el primer factor negativo hay que remontarse a los albores de la Modernidad. En aquella época la historia del arte, la crítica de arte y la estética surgieron de la misma materia prima, pero tomaron caminos separados, a pesar de que la unión habría sido la mejor opción para una profesionalización de los estudios de historia del arte, carrera que aglutina las disciplinas anteriores, sin olvidar que existen otras enseñanzas con las que comparte contenido.

Por desgracia la formación académica no está lo suficientemente enfocada a las numerosas salidas laborales. Esto conlleva que, a pesar de nuestra especificidad, tengamos que desarrollar estudios superiores como un máster o un postgrado para especializarnos en algo que, en la mayor parte de los casos, ya hemos dado directamente o de forma transversal en varias asignaturas. Está por ver si las modificaciones del Plan Bolonia (prácticas en empresas o trabajos de fin de grado) surten efecto, pero la crisis ha impedido que puedan valorarse objetivamente estos cambios.

Otro factor que nos perjudica es el intrusismo laboral que padecemos, pues pocos casos hay tan vilipendiados como el nuestro. Nadie duda acerca de las diferentes competencias, estudios y responsabilidades entre dos puestos de trabajo distintos de un mismo sector: doctor-auxiliar de enfermería o arquitecto-albañil, por ejemplo. En esos casos las delimitaciones son cla- ras y cualquiera de los puestos es respetado porque se conoce y se asume su importancia en la consecución de los objetivos. En el caso de la profesión sobre la que se debate aquí, el retraso con el que se estableció en España ha provocado que las instituciones públicas y privadas no hayan tenido en cuenta nuestra formación específica, por lo que seguimos sin tener nuestro lugar en beneficio de otras formaciones absolutamente diferentes o menos preparadas que la nuestra. La realidad habla mejor que nosotros. Hay una baja presencia de historiadores del arte en centros de restauración, donde nuestra presencia es fundamental para la catalogación o estudio iconográfico; lo mismo sucede con el estudio de piezas en excavaciones arqueológicas; el inventario y desarrollo de informes previos a intervenciones para la puesta en valor del patrimonio cultural; la gestión cultural (a partir de nuestra formación) en disciplinas como la museología y la museografía; el campo investigador, para seguir escribiendo la historia del arte y ser una ciencia útil para la sociedad del conocimiento, etcétera.

Las instituciones públicas deben tener en cuenta al profesional de la historia del arte pues, si tan importante es el patrimonio cultural en España, que se demuestre con la defensa de aquellas formaciones más aptas para su gestión y revalorización. Y pocos, muy pocos son los casos en los que las empresas culturales que trabajan con patrimonio cultural cuentan con nosotros. Excluimos a El Gremio Diseño (Ciudad Real), donde tuvimos la fortuna de trabajar los cuatro historiadores del arte que firmamos este artículo, por eso nuestra opinión está basada en la experiencia.

Además, nuestra formación nos capacita para la educación, como rama de las ciencias sociales. Particularmente, a educar a través del arte, al sumar el 
a debate Historiadores del arte ¿para qué? Una titulación en busca de una profesión | coordina José Castillo Ruiz

antiguo CAP o el nuevo máster de secundaria (otro tema que daría mucho que hablar). Pero nuestras oposiciones son conjuntas con historia y geografía, y este tema daría para otro debate, aunque, nos gustaría añadir que un país que vive del turismo a unos niveles de tal magnitud debería valorar de forma muy seria una adecuada puesta en valor de su patrimonio cultural, comenzando por el aumento de horas lectivas en asignaturas relacionadas con el mismo.

Y en la comparación con los guías turísticos, evidentemente, somos críticos. Desde luego, la defensa de nuestros intereses, estudios y salidas laborales les afectará, pero es una absoluta vergüenza que en un país con el número y valoración de nuestro patrimonio, el historiador del arte no esté capacitado por su formación para ejercer esta profesión.

Existe un problema muy grave y es, sin duda, la falta de unión entre los historiadores del arte. No tenemos una institución que nos ampare y que defienda nuestros intereses comunes. Debemos actuar lo antes posible para establecernos como un único frente que trate de demostrar a la sociedad que tiene una profesión con unas elevadas cotas de responsabilidad cultural y social. Además, hay guerras internas entre patrimonialistas e historiadores que no hacen más que desangrarnos mientras nos vamos desnortando cada día más.

Necesitamos urgentemente un organismo, una asociación o una federación que defienda a los historiadores del arte para que se reconozca que somos una figura formada y capacitada en esencia para la gestión del patrimonio cultural. Como ejemplo de que necesitamos ocupar este lugar, basta con echar un vistazo a la gestión pública y a la gestión privada del patrimonio en
España para darse cuenta de que algo falla. $Y$ es que, en la mayoría de los casos, falta formación. ¿Acaso va a interesarse de igual manera en seguir reciclándose y actualizándose una persona que no conoce el terreno formativo que otra que ha estudiado para obtener una licenciatura o un grado, tan relacionado con el ámbito de la gestión?

Pocas son las esperanzas que mantenemos. Somos un país poco permeable y aún menos acostumbrado a reconocer y subsanar errores propios. La solución quizá se encuentre en el esfuerzo constante para demostrar nuestra valía, tendiendo la mano hacia la interdisciplinariedad, pues hablar de la historia del arte es hablar de historia, de literatura, de sociedad... y por ello debemos ser transparentes a otras disciplinas, y demostrar que podemos trabajar juntos, aunque sin pisar el terreno del otro, reclamando nuestro espacio, tal y como hacen el resto de carreras universitarias. 